\title{
Raising Awareness of Anaerobic Digestion in the UK- Views of Key Stakeholders
}

\author{
Franklin I. Duruiheoma (Corresponding author) \\ Department of Biological Sciences, University of Chester \\ Parkgate Road, Chester CH1 4BJ, United Kingdom \\ E-mail: f.duruiheoma@chester.ac.uk \\ Cynthia Burek \\ Department of Biological Sciences, University of Chester \\ Parkgate Road, Chester CH1 4BJ, United Kingdom \\ E-mail: c.burek@chester.ac.uk
}

Graham Bonwick

North West Food Research Development Centre, University of Chester

Parkgate Road, Chester CH1 4BJ, United Kingdom

E-mail: g.bonwick@ chester.ac.uk

\author{
Roy Alexander \\ Department of Geography and Development Studies, University of Chester \\ Parkgate Road, Chester CH1 4BJ, United Kingdom \\ E-mail: r.alexander@chester.ac.uk
}

Received: September 28, 2014 Accepted: Dec. 11, 2014 Published: December 31, 2014

doi:10.5296/jee.v5i2.6366 URL: http://dx.doi.org/10.5296/jee.v5i2.6366 


\section{Abstract}

Meeting rising energy demand and sustainable development goals at the same time is a major challenge for policy makers in the $21^{\text {st }}$ century. The situation is further stressed by a rising world population, climate change, natural disasters and food security concerns. Renewable energy technologies such as anaerobic digestion (AD) proffer one solution for policy makers to overcome some of the challenges to sustainable development. The technology has been widely adopted in some parts of Europe (e.g. Germany, Denmark, Austria and Sweden), the United States and also parts of Asia and Africa. However in the United Kingdom (UK), the technology is under-developed, as was recognised in its anaerobic digestion strategy and action plan of 2011. This study focused on identifying options for raising awareness of AD technology in the UK. 21 key stakeholders divided into groups according to their expertise, were interviewed to explore their views on the areas of focus in the UK strategy and action plan regarding raising awareness of the technology. The results revealed that aligning AD with sustainable development goals, community AD and localism, small AD plants, provision of an available market for $\mathrm{AD}$ products, building UK skills and diversifying biogas use from $\mathrm{AD}$ are positive options for raising awareness of $\mathrm{AD}$ in the UK. Challenges to these options and possible solutions to the challenges were also identified and discussed.

Keywords: Anaerobic digestion, Sustainable development, Renewable energy technology, Promotion, Stakeholders 


\section{Introduction}

Since the concept of sustainable development was introduced in 1987 by the World Commission on Environment and Development (WCED 1987), there have been a number of initiatives and policies aimed at ensuring sustainable resource use in different parts of the world. While most policy makers are keen on making decisions that will ensure economic viability, environmental health and social well-being in light of sustainable development goals (Bi and Haight 2007), the rising demand for energy all over the world exerts pressure on some strategic natural resources such as oil and gas, coal, and uranium thereby necessitating the need for renewable energy initiatives (Swindal et al. 2010; Kim et al. 2010; Alburquerque et al. 2012; Browne et al. 2013). Although the rise in renewable energy demand can be linked to economic, environmental and political events across the globe like population growth, food security concerns, need to reduce greenhouse gas emissions and climate change, it also indicates the role of technological advancement in promoting efficient resource use. This was fertilizer in FAO's definition of sustainable rural development which according to Anon (1989) is the conservation and management of natural resources, and preference for institutional and technological changes that support sustainable development goals. Anaerobic digestion (AD) is a typical example of renewable energy technology that can help to achieve sustainable development goals in the $21^{\text {st }}$ century.

$\mathrm{AD}$ is the natural process by which organic materials are broken down by bacteria to yield biogas constituting mainly of methane $\left(\mathrm{CH}_{4}\right.$, between $\left.40-70 \%\right)$ and carbon dioxide $\left(\mathrm{CO}_{2}\right)$ and a residual nitrogen-rich fertilizer know as the digestate. In $\mathrm{AD}$ plants however, several modifications allow control of this process to yield specific amounts of biogas and regulate energy generated and consumed. AD plants have been applied in different sectors such as industrial power generation, electricity generation, community waste treatment, and for agricultural purposes across the globe (Zglobisz et al. 2010; Bywater 2011; Wilkinson 2011). Traditionally, AD application in the UK has been mainly in the area of wastewater (sewage sludge) treatment, notwithstanding its widespread use in electricity generation in other parts of Europe like Austria, Denmark, Germany, and Sweden (Lukehurst 2007; cited in Zglobisz et al 2010). There is also a general increase in interest in $\mathrm{AD}$ for agricultural application owing to the large amount of biodegradable waste from this sector, and the need for its effective management (Alburquerque et al. 2012).

AD provides benefits in terms of renewable energy generation, waste treatment and organic fertilizer (digestate). It can also help minimize greenhouse gas (GHG) emissions (Levidow and Papaioannou 2013) and reduce the amount of waste sent to landfill (Zglobisz et al. 2010). Despite these significant benefits, the UK AD industry is still under-developed. The UK AD strategy and action plan, published in June 2011 identified the benefits of AD, acknowledged its under-developed status in the UK and outlined the various themes to be addressed with regards to AD (Department for Environment, Food and Rural Affairs (DEFRA) 2011). The action plan and strategy report however claimed that there is a general awareness of AD in the UK, even when an earlier working document on AD gap analysis in the UK contradicted this and reported low levels of awareness as one of the gaps (Frith and Gilberth 2011). Another DEFRA (2012) report on AD progress published one year after the introduction of 
the action plan and strategy clearly stated the need to raise awareness of AD technology and to promote its benefits. Furthermore, the fewer than 200 AD plants in the UK indicate a relatively low level of awareness compared to elsewhere in Europe, e.g. Germany, has well over 6000 AD plants (Parliamentary Office of Science and Technology, 2011).

It is important to state that although the UK seems to have specific barriers to the development of $\mathrm{AD}$, there are certain generic limitations to its development as a renewable energy technology:

- High cost associated with AD plants in terms of finance and time (Zglobisz 2010; Bywater 2011);

- Low level of knowledge and understanding of $\mathrm{AD}$ plants and consequent poor maintenance and operational failure. Lukehurst (2007 cited in; Zglobisz 2010) highlighted this barrier as the main reason why only $25 \%$ of $\mathrm{AD}$ plants installed in the 1990s are still functional; and

- Digestates from AD plants are not fully accepted as a rich source of plant nutrient by farmers (Alburquerque et al 2012; Thomsen et al. 2013). This has greatly affected the available market for digestates.

Other specific challenges to AD technology in the UK include issues surrounding policy and legislation regarding siting approval and the number of governmental agencies associated with AD regulation (Bywater 2011).

To this end, the aims of this research are to identify the various options available for raising awareness of $\mathrm{AD}$ in the $\mathrm{UK}$ and the ways to address some of the challenges to $\mathrm{AD}$ development both in the UK and more generally.

\section{Methodology}

Qualitative data used for this research were derived from interviews with key stakeholders in UK AD industry. The wording items used in the interview questions were based on the gap analysis of UK AD industry by Frith and Gilberth (2011). The interview questions were therefore focused on addressing the issues associated with raising awareness of AD in the UK as covered by the report. The interview questions were structured to ensure uniformity of the data and to allow direct comparison across the various stakeholders interviewed. The need for rigidity of the data is to ensure tight focus on the issues concerning raising awareness of AD in the UK contained in the gap analysis report of 2011. Interviews were conducted by means of electronic mail. This type of interviewing is known as asynchronous communication of time and place (Opdenakker 2006). The main advantages of this interview technique are ease of contact with large number of respondents and the acquisition of verbatim interview responses for analysis.

A total of 202 AD stakeholders in the UK were contacted and 21 agreed to be interviewed. Informed consent was also obtained from the 21 stakeholders for publishing their responses, while ensuring anonymity by using pseudo names. Distribution and some characteristics of the participating 21 stakeholders are presented in Table 1 . The stakeholders were divided into 
six different groups and criteria for selection varied. The groups were:

- Conservationist academics (Group A): This refers to those with established interest in nature conservation, renewable energy technology and sustainable development. They are based in institutions of higher learning, mainly universities. Selection and sampling of stakeholders in this category was through publications (research articles, reports and conference proceedings). A snow-balling approach was also used here as referrals were sometimes received.

- Conservationist non-academics (Group B): Similar to group 'A', in the sense that they have established interest in nature conservation, renewable energy technology and sustainable development. In this case however, they are not based in institutions of higher learning, and do not engage in teaching at universities. They are based in research institutes, and other supporting non-governmental conservation agencies and associations. This group is distinguished from group ' $\mathrm{A}$ ' because, their views on issues raised might be expected to differ from those in the academies. Stakeholders in this category were selected and sampled through publications and official websites of relevant institutes, organisation and agencies.

Table 1. Characteristics and distribution of AD stakeholders interviewed

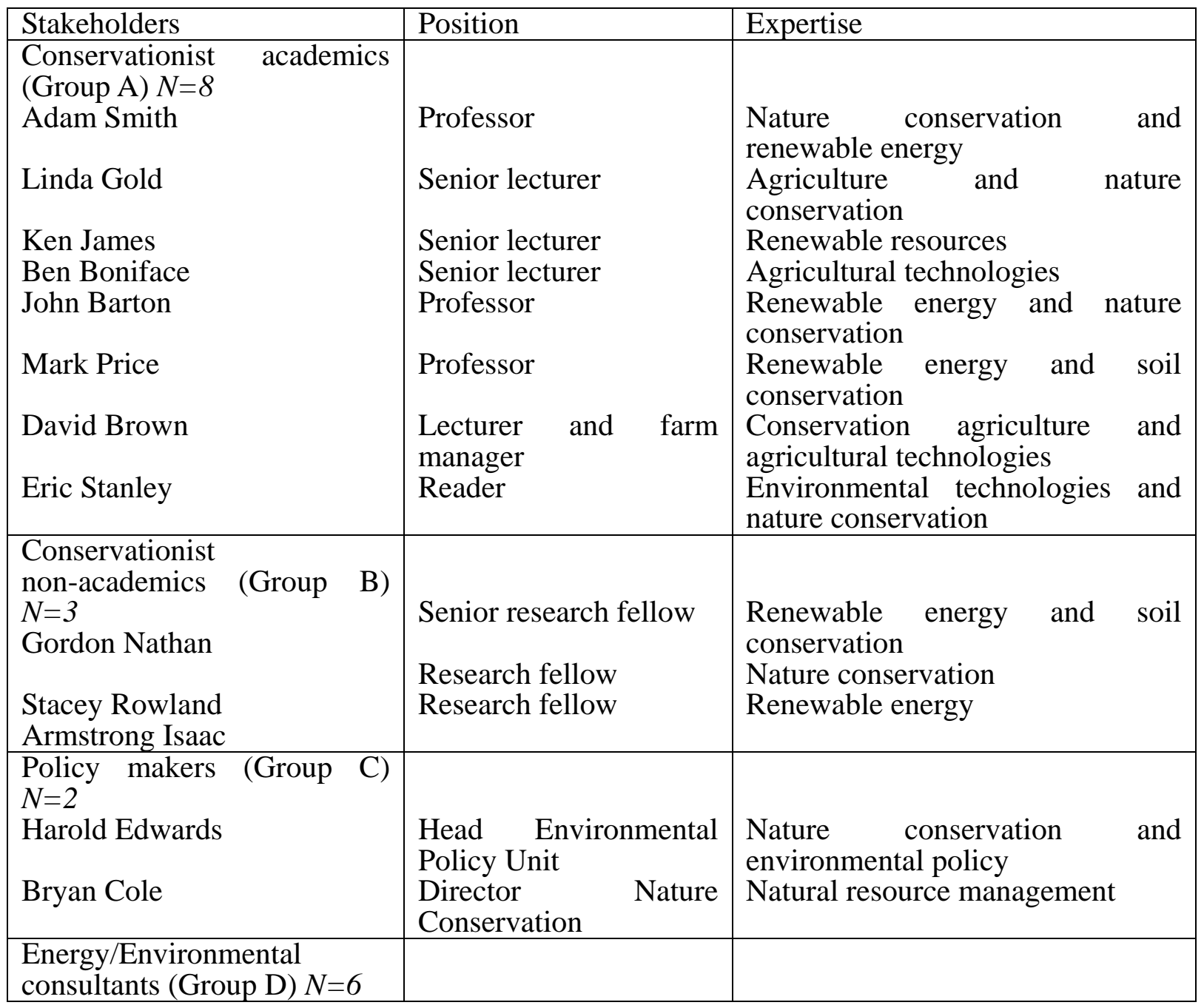




\begin{tabular}{|c|c|c|}
\hline Max Payne & Lead consultant & $\mathrm{AD}$ and biogas technology \\
\hline Nick Jonathan & Consultant & \\
\hline Joanne Brennan & Senior consultant & $\begin{array}{l}\text { AD and environmental } \\
\text { technologies }\end{array}$ \\
\hline Tricia David & Consultant & \\
\hline Iain Duke & Principal consultant & $\mathrm{AD}$ and renewable technology \\
\hline Sharon Murray & Consultant & $\mathrm{AD}$ and biogas technology \\
\hline $\begin{array}{l}\text { Key figures in farmers } \\
\text { association } \\
\text { (Group E) } N=1 \\
\text { Paul Andrew }\end{array}$ & Regional head & $\begin{array}{l}\text { Agriculture, environmental } \\
\text { policies and administration }\end{array}$ \\
\hline $\begin{array}{l}\text { Retailers (Group F) } N=1 \\
\text { Deborah Carter }\end{array}$ & $\begin{array}{l}\text { Head sustainability and } \\
\text { agriculture }\end{array}$ & $\begin{array}{l}\text { Sustainable } \\
\text { agriculture }\end{array}$ \\
\hline
\end{tabular}

Note: $N=$ number of participants, and all names presented here are pseudo names

- $\quad$ Policy makers (Group $C$ ): This group includes those individuals associated with policies relevant to natural resource conservation and renewable energy in the UK. The group is drawn from regulatory agencies and societies across the UK. Stakeholders here were selected mainly through official websites of the relevant bodies and government reports.

- Energy/Environmental consultants (Group D): This group refers to those individuals with expertise in energy and or environmental consultancy with specific interest in AD. Selection and sampling of stakeholders in this group was through relevant websites.

- Key figures in farmers association (Group E): This group comprises of heads of associations and unions that protect the interest of farmers within the UK. They were selected and sampled through relevant association and union websites.

- Retailers (Group F): This group focus was on sustainability and agricultural heads in major retailers within the UK.

The questions were slightly different from one participant group to another, but groups ' $\mathrm{A}$ ' and ' $B$ ' were given the same questions, as were groups ' $C$ ' and ' $D$ '. This was done to ensure that questions asked suited participant group expertise. Table 2 shows the distribution of questions across the groups of participants. The interviews with these stakeholders were structured in the sense that questions asked were informed by themes already identified in the UK AD gap analysis report of 2011. The analysis was therefore focused on coding the responses into themes and fitting these responses into the research text. MAXQDA 11 statistical software was used to analyse the interview data.

Table 2. Interview question distribution across participant groups 
1. How can we ensure that the benefits of AD technology are $\mathrm{C}, \mathrm{D}, \mathrm{E}$ and $\mathrm{F}$ shared by everyone?

2. How can the understanding of AD technology be enhanced by all those associated with AD facilities?

3. Do you consider community $\mathrm{AD}$ and localism have an All groups important role in UK's AD strategy and action plan?

4. How can we promote community $\mathrm{AD}$ projects in view of sustainable development goals?

5. Do you consider small $\mathrm{AD}$ plants as integral to raising $\mathrm{A}, \mathrm{B}, \mathrm{E}$ and $\mathrm{F}$ awareness for AD?

6. How can we ensure that biogas generated from $\mathrm{AD}$ plants is $\mathrm{A}, \mathrm{B}, \mathrm{C}$, and $\mathrm{D}$ diversified in their use?

\section{Results and Discussion}

\subsection{Promoting AD Projects in View of Sustainable Development}

Figure 1 shows a summary of responses received from participants on each theme (interview questions) and sub-theme (shared opinions). The most shared opinion for promoting AD in view of sustainable development was informing people about the benefits of AD. A detailed response that covered the three elements of sustainable development was that of a policy maker who stated:

'By promoting $A D$ as a profitable supplier of renewable energy from waste, a creator of local jobs / skilled labour force and potentially a source of sustainable income for communities to re-invest in their own future. Potential health benefits alongside wider environmental benefits. Furthermore, a by-product of AD could be used as a fertilizer, which can help support the sustainability of rural economies. AD plants themselves potentially offer a focus for engaging communities to think about their energy future and to gain a better understanding of the whole life of food'.

Earlier, Wilkinson (2011) reported that in some developing countries AD is often linked to sustainable development initiatives, natural resource conservation and regional development strategies. In the UK, discussions about promoting $\mathrm{AD}$ have been focused on the role of $\mathrm{AD}$ in treating biodegradable waste, thereby reducing the amount sent to landfill (Zglobisz et al. 2010). By diverting biodegradable waste from landfill part of the environmental goals of sustainable development is achieved. It is important to note that, even when AD yields sustainable development goals, it could still be unsustainable if residual digested materials are not properly reused, treated or disposed of as this can cause negative environmental impact (Alburquerque et al. 2012). 


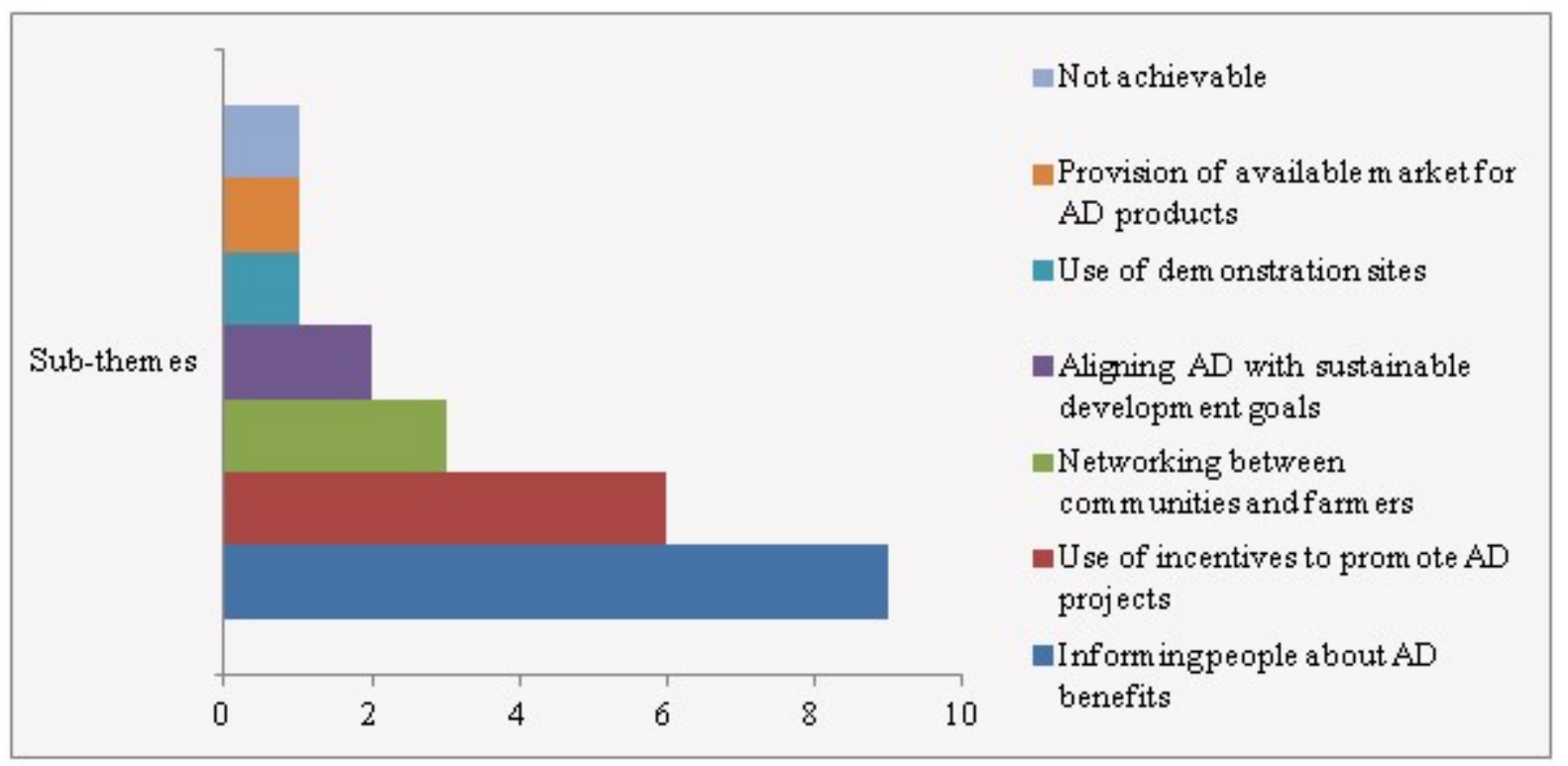

Figure 1. Summary of total response across sub-themes under promoting AD projects in view of sustainable development

Another shared opinion among participants was the use of incentives to promote AD projects. Participants suggesting this option were mainly focused on the role that government has to play in the development of AD projects and how communities can be encouraged to accept such projects. The main suggested role for the government was financial support as one group A participant said 'financing $A D$ at all scales (large, medium and small)'. There was also a call for networking between communities and farmers. Again, there is a need for government support but in this case non-financial, rather the coordination of the network between farmers and communities, like David Brown, an academic conservationist stated, 'The government need to promote more and encourage communities to work with farmers and not against them'.

Aligning AD with sustainable development goals was another shared opinion. By aligning $\mathrm{AD}$ with sustainable development goals, AD plants should use biodegradable waste rather than emphasize growing energy crops. Other isolated opinions are the use of demonstration sites and the provision of available market for AD products. The use of demonstration sites was suggested by a group D participant, who opined that this would allow more public involvement. The provision of available market for AD products was a suggestion of another group D participant. AD products like the biogas, digestate and energy need to be supplied to the market to make AD sustainable. Lack of available markets for biogas was described as one of the factors that have made AD unsustainable over the years (Wilkinson 2011). Although most participants made suggestions as to how $\mathrm{AD}$ can be promoted in view of sustainable development goals, the group E participant, contradicted this and believes that AD cannot compete with other commercial business as he said 'Difficult, I think commercial business are far better placed to make a success of this technology (AD)'. Three other participants did not respond to this question. 


\section{Macrothink}

3.2 Community $A D$, localism and the UK's AD strategy and action plan

Community $\mathrm{AD}$ and localism were identified as the main option for raising awareness of $\mathrm{AD}$ in the UK AD strategy and action plan, and this gained a wide acceptance among participants in this study. Figure 2 shows a total of 17 participants out of the 21 interviewed were in support of community AD and localism. The areas of support were that community AD and localism would promote community acceptance of $\mathrm{AD}$, allow communities to benefit directly from $\mathrm{AD}$ and minimisation of cost.

According to one group A participant, community $\mathrm{AD}$ and localism 'will increase the likelihood of public support of AD facilities and remove potential stigma that drives nimbyism'. Similarly, the direct benefits of AD will give the community a sense of ownership and inevitably their acceptance of $\mathrm{AD}$ as suggested by another group A participant, who stated:

'Yes since at community level there is a better understanding of the real needs and circumstances of the area, therefore AD treatment can be more targeted and tailored to existing needs. Again, community AD plants promote local 'ownership' of facilities which increases the willingness to participate and 'buy in' to the idea'.

Community acceptance of AD plants was earlier identified as a challenge to the development of the technology (Khan 2002; cited in Boholm and Löfstedt (Eds.) 2005).Other expected benefits of $\mathrm{AD}$ in a local community are job creation, waste management, free power and heat. Community AD projects in Sweden, already feed local households with heat and power (Wilkinson 2011).

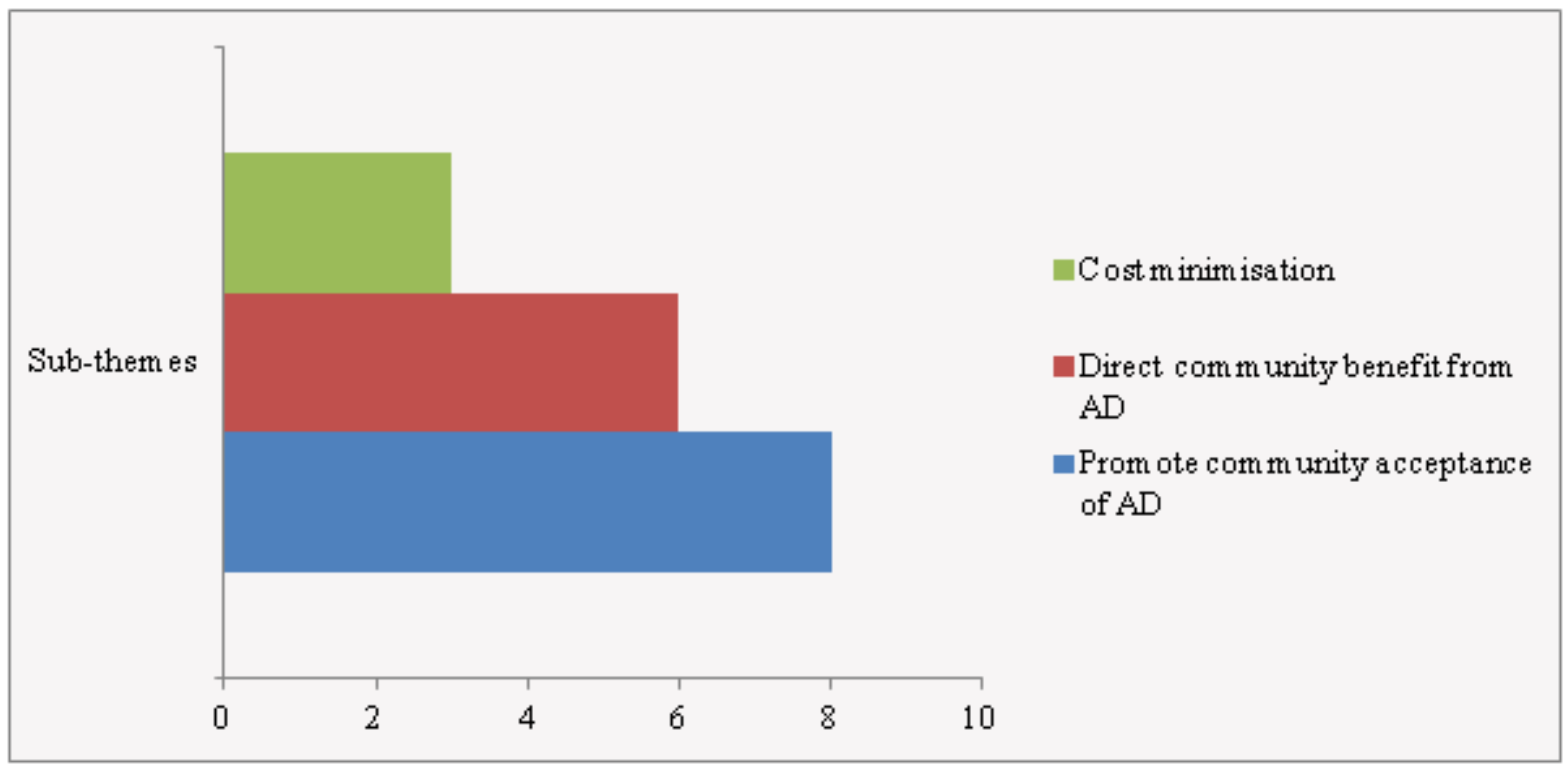

Figure 2. Summary of total response across sub-themes under community AD, localism and the UK's AD strategy and action plan

Amidst the wide acceptance of community AD and localism among respondents, some participants identified the potential challenges to achieving this. The challenges identified 
were environmental pollution and hazards, access to the technology and funding. With respect to environmental pollution and hazards, a group B participant said, 'At the same time, $A D$ plants are dangerous and have the potential to cause considerable pollution, and having them run by a larger number of people with possibly fewer resources available to invest in training and AD management is likely to increase the risk of serious accidents and pollution incidents'. The main concern about accessing the technology is that $\mathrm{AD}$ plants are more complex systems when compared to wind turbines or solar panels. With funding, the group $\mathrm{E}$ participant who is not in support of community $\mathrm{AD}$ and localism simply responded, 'Nocommunity $A D$ has been difficult due to the logistics and cost of transporting/handling inputs and removing digestate'. This response is in absolute contrast to the suggestion that community $\mathrm{AD}$ and localism will minimize cost.

Some participants also mentioned certain factors that should be considered with community AD. Networking with farmers, proximity to feedstock and size of the digester were the factors mentioned. The suggestions were that farmers would provide the land and most of the feedstock, and so the digesters should be closer to farms. As for the size of the digester, one group D participant stated:

'We have also looked at these micro digesters for food waste in a village, since it means that there are not huge food waste miles and the digestate could be used locally on a farm or amenity land'.

Another consideration in developing community $\mathrm{AD}$ identified in literature is that, such projects should avoid biomass loss in the form of deforestation and also possible soil erosion (Perez et al. 2014).

\subsection{Small AD Plants and Awareness of AD}

The idea of community $\mathrm{AD}$ and localism require the use of small scale AD plants. The question relating to this was not addressed to all participants as shown in Table 2, and Figure 3 shows the total responses under this theme. From the responses received, small AD plants have economic, environmental and geographical merits. The most shared opinion was on the economic merit. For example, Ken James (group A) simply said, 'economics would stack up to make small scale AD plants economic'. Reducing transport costs was one of the areas identified to provide economic benefits. Environmental merits identified are same as those with large $\mathrm{AD}$ plants, which is the use of farm and food waste thereby minimizing the amount sent to landfill and reduction in greenhouse gas emissions. Geographically, some participants believe that small AD plants can make AD popular at local level. One group A participant shared these three merits of small AD plants when he said:

'They not only raise awareness but also spread them geographically so that transport costs and associated environmental impacts are decreased'.

Social merits like social cohesion, improvement in quality of life and values can also be derived from small AD plants (Wilkinson 2011).

The main challenge to small AD plants identified by one participant was cost, which does not 
correspond to economic merits identified by other participants. A similar contradiction was noted in the results pertaining to community $\mathrm{AD}$ and localism. In this case however, the participant who suggested this challenge did so with a question when he said, 'how much would it cost to set up an on-farm facility, even simply to deal with waste effluents (e.g. from a dairy herd)?'

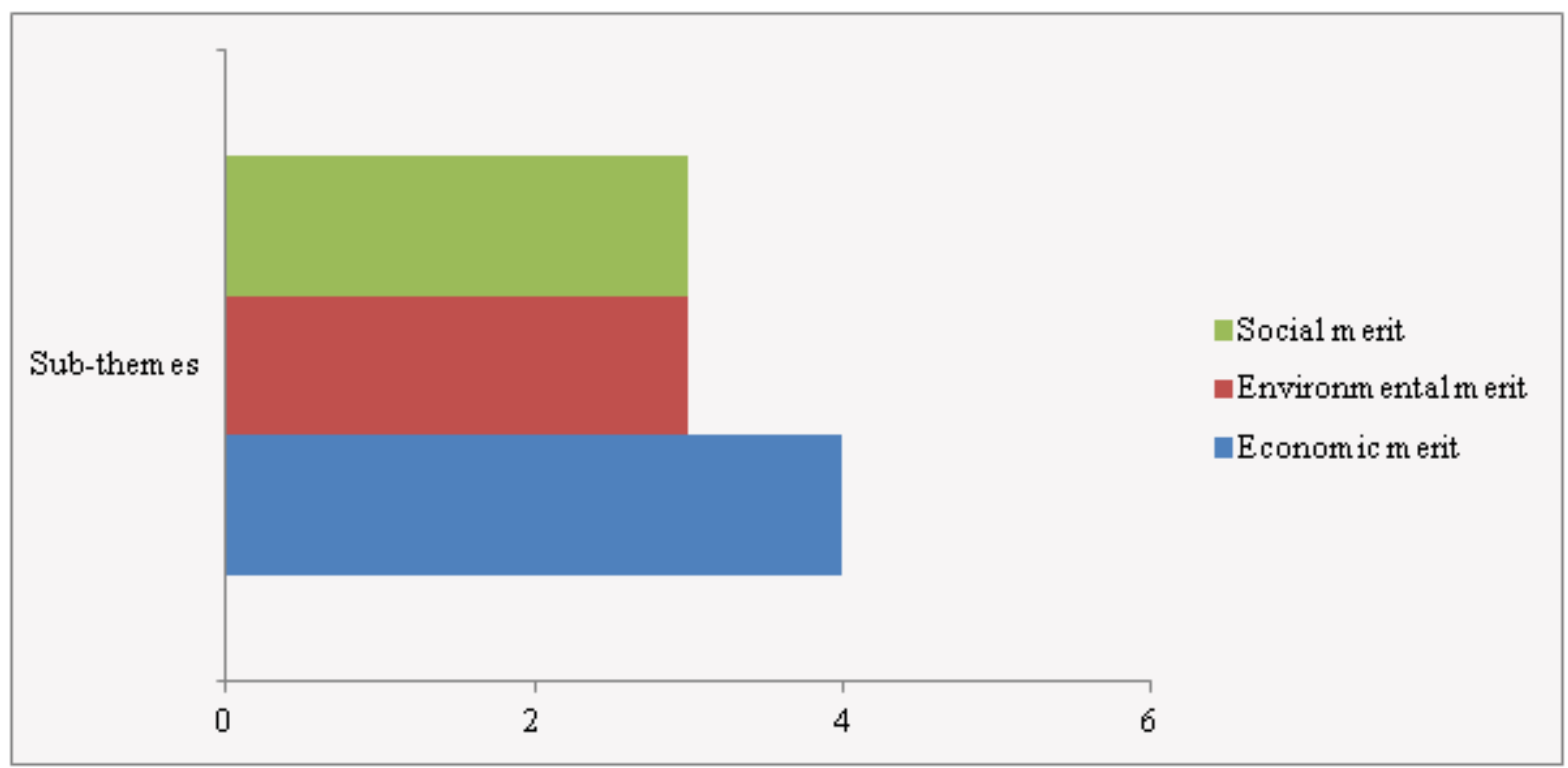

Figure 3. Summary of total response across sub-themes under small AD plants and awareness of $\mathrm{AD}$

The contradiction around the issue of cost requires comprehensive economies of scale in deciding the size, type and method for which AD technology can be used, because the arguments of both pro-small AD plants and anti-small AD plant participants remain valid. It is therefore important to address the problem of 'cost' of $\mathrm{AD}$ development identified by participants of this study and also in the literature (e.g. Zglobisz et al. 2010; Bywater 2011) as it affects the development of $\mathrm{AD}$ at all scales.

\subsection{Enhancing the Understanding AD Technology by Those Associated with AD Facilities}

Building UK skills is one of the priority areas of DEFRA as indicated in the AD gap analysis of 2011 and UK AD strategy and action plan. Similarly, Lukehurst (2007 cited in; Zglobisz 2010) identified inadequate knowledge and skills as one of the challenges that has limited the development of the $\mathrm{AD}$ industry in general. This challenge can also impact on the environment, for example Ingram (2008) suggested that poor knowledge and lack of experience in new and complex technologies and practices is one of the constraints to sustainable soil management. The interviews revealed three important methods for enhancing the understanding of $\mathrm{AD}$ technology. It also showed the preparedness of AD stakeholders in the UK to move the technology forward, taking into account the number of shared opinions. The interview question relating to this was distributed to all participant groups except group $\mathrm{F}$. 


\section{Mll Macrothink}

The three methods suggested by participants are education (demonstration and training), promoting AD product and sharing experience as illustrated in Figure 4. Demonstration and training were paired as a single method because in reality it is difficult to isolate one from the other, and they both share the common goal of educating people. This method was shared by 13 participants cutting across all groups interviewed, and some went on to include factors to be considered before using demonstration or training. For instance, a group D participant explained:

'Training and demonstration forums, depending on the area targeted and getting the general public and planning authorities involved. This would also cost money in advertising as well as time in doing an analysis and making a careful selection of places to use'

Based on this explanation, it is important to consider target audience and area, cost and time factors before using the demonstration and training for enhancing knowledge of AD technology. Participants who suggested the promotion of AD products will enhance the understanding of the technology seemed to be concerned with how farmers and investors can be made to develop interest in the technology. Eric Stanley (group A) said, 'Providing the products as convenient and cheap alternatives to artificial fertilizers while promoting their wider benefits will permit farmers to enjoy the feel good factor at no extra cost to them'.

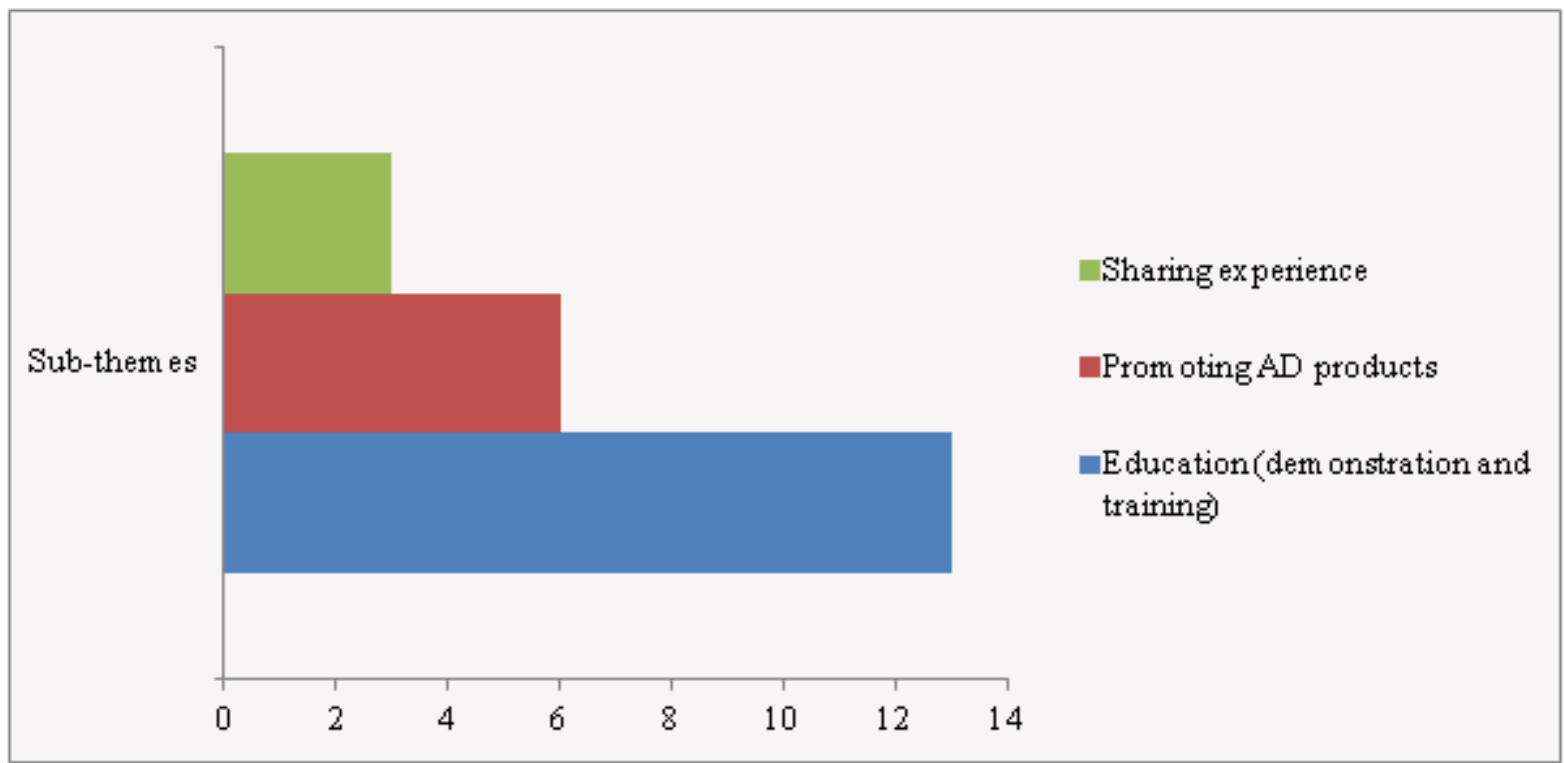

Figure 4. Summary of total response across sub-themes under enhancing the understanding $\mathrm{AD}$ technology by those associated with $\mathrm{AD}$ facilities

By encouraging farmers and other investors to develop interest in the technology, the next stage will be to educate them on AD through training or demonstration. The promotion of AD products can therefore be seen as a preceding stage to demonstration and training, if the process of enhancing the understanding of $\mathrm{AD}$ was to be in stages. Sharing experience is the informal method of the three methods identified for enhancing the understanding of $\mathrm{AD}$. 
According to one group $\mathrm{C}$ participant, it involves learning through shared experience in the industry'. From the responses received, there seems to be a lack of sharing of experience within the UK AD industry as one group A participant explained:

'Those associated with AD facilities should share their experience with other people active in the same sector as well as with the public. Currently the limited sharing and exchanging of information hinders the understanding and improvement of $A D$ technology'.

3 out of the 20 participants neither made any suggestion nor shared any opinion on this issue.

\subsection{Ensuring the Benefits of AD are Shared by Everyone}

The question covering this theme was asked to 10 participants excluding those in group A and $\mathrm{B}$ and Figure 5 shows the total responses and sub-themes. Despite the low number of participants, there were several opinions expressed on how we can ensure the benefits of AD are shared by everyone, including those who feel this is not achievable. The most shared opinion was using the benefit of $\mathrm{AD}$ for general purposes, like a group $\mathrm{C}$ participant said, 'grid injection and vehicle usage of biogas, national grid connection to electricity generators'. With the digestate, a group D participant interestingly suggested that using the digestate as fertilizer for crop production in the UK is a benefit for all. Another option noted was raising awareness, and according to Bryan Cole (group C) 'this should be the main goal of awareness. People should be told about the benefits of AD through awareness programs'. The environmental benefit of AD can also be shared by all directly or indirectly. The group $\mathrm{E}$ participant opined that the reduction in greenhouse gas emissions, especially methane, and its utilization as a renewable energy source is an environmental benefit shared by all. The direct benefit is the use of organic waste as feedstock for $\mathrm{AD}$, and this is being promoted by the government as stated by one group D participant, who said, 'Government and councils have waste collection schemes set up so that the public know where their waste is going to and to be used to generate heat/electricity'. Networking with AD owners to ensure best practice was an isolated opinion by another group D participant. Two participants, both from group D, suggested that it will be difficult to ensure $\mathrm{AD}$ benefits are shared by everyone. According to them the main challenges will be conflict of interest and critics of the technology. 


\section{Macrothink}

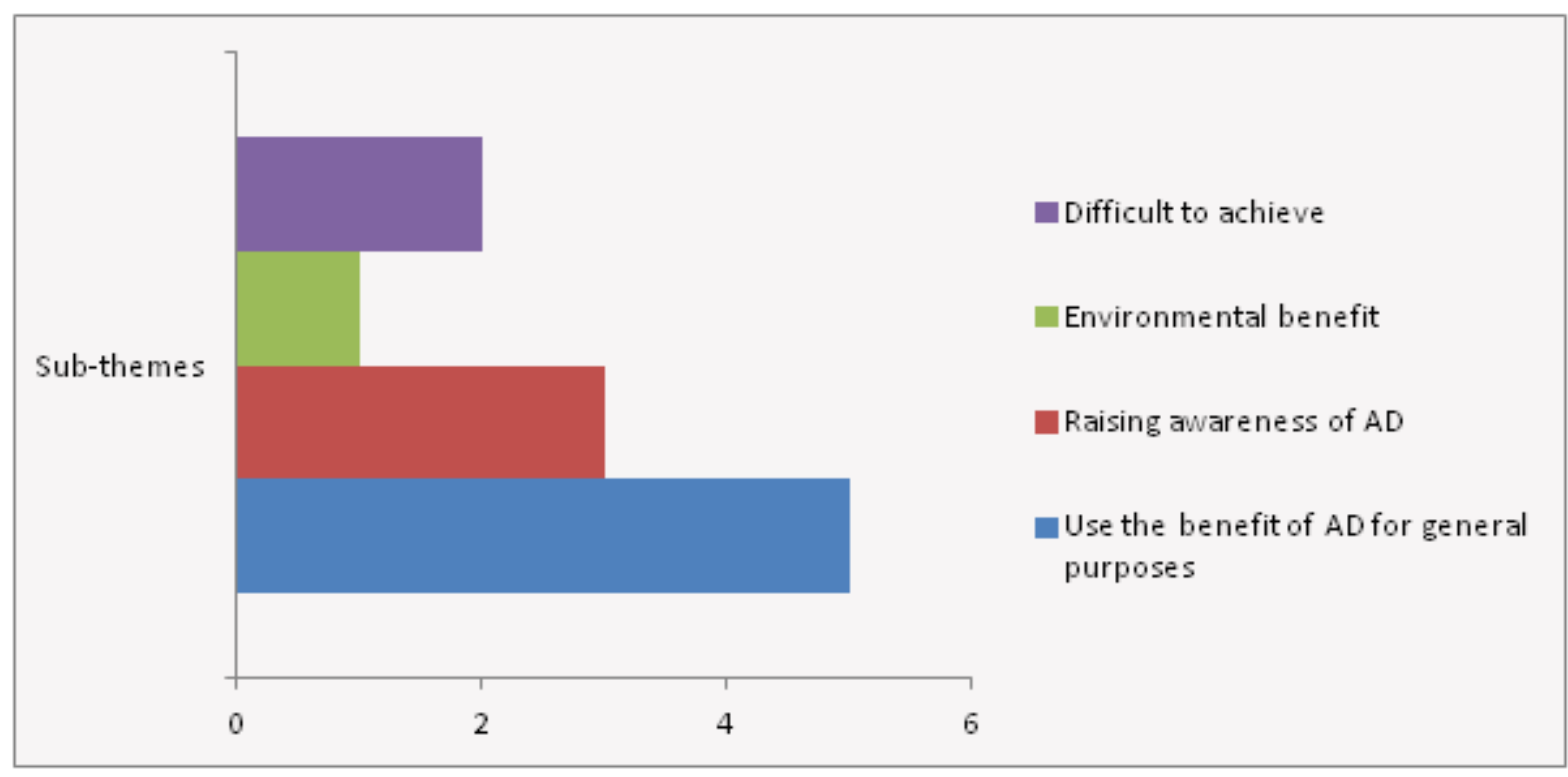

Figure 5. Summary of total response across sub-themes under ensuring the benefits of AD are shared by everyone

\subsection{Diversifying biogas use from $A D$}

Biogas from AD remains the most pronounced benefit of the technology. The importance of this enquiry is that provision of an available market for biogas, mainly methane, and efficiency in its use is a top priority area of DEFRA. In section 3.1, the importance of available market for biogas was also discussed. All groups of participants except $\mathrm{E}$ and $\mathrm{F}$ (Table 2) were asked this question. The response distribution is represented in Figure 6. Participants who suggested this added that such heat and electrical energy could be used for farm-houses and vehicles, or supplied to the local community. Injection of biogas into the national grid was also identified as an option. One group B participant went on to describe this as the likely most efficient use when he stated 'probably the most efficient use would be if biogas could be connected into national gas grid'. Some participants also identified the use of biogas from $\mathrm{AD}$ in vehicles and other operations that make use of fossil fuels. Biogas from $\mathrm{AD}$ can also be used for cooking and refrigeration as seen in most developing nations, but this type of application is less likely in developed nations such as the UK (Surendra et al. 2013). 


\section{Macrothink}

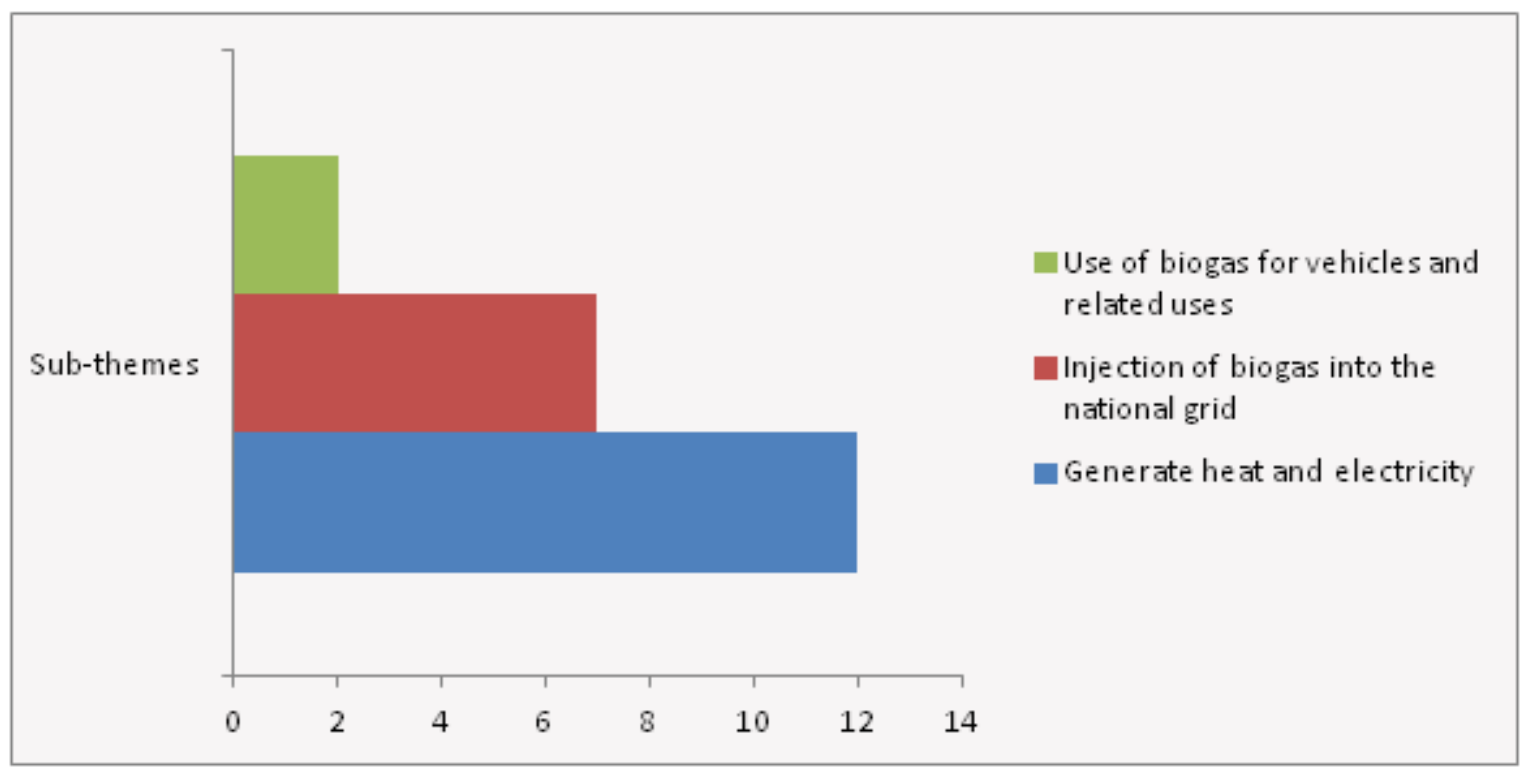

Figure 6. Summary of total response across sub-themes under diversifying biogas use from

$\mathrm{AD}$

A number of factors to be considered before the biogas from AD can be diversified in its use were also noted by some participants. One such factor is the issue of proximity of AD plants to end users of the biogas, as one group A participant clearly stated: 'currently the setting of $A D$ plants does not normally consider the proximity of potential end users of $A D$ biogas and this restricts its use. Integrated planning is needed to ensure that the maximum benefits are derived'. Considerations like size of the $\mathrm{AD}$ plants and the need for better financial incentives to achieve this were also identified, as contained in the response of a group D participant, who explained:

'Support for AD MUST be separated from other properly renewable energy (RE) technologies, such as solar panels and the fact that it is even included in such an incentive regime illustrates how completely misguided and misinformed policy-makers really are. If we speak of the technology as a renewable energy technology, we subliminally look to it to produce energy, rather than to treat waste in an environmentally responsible manner which is where it is (properly) used and incentivized everywhere else in the world outside Europe. If we regard $A D$ as a RE technology, there is almost no point in putting low-gas-producing organics into AD plant - and we would have German-style maize monoculture which is what has given rise to ILUC legislation which will hit the British $A D$ industry in a very short time. Thus, unlike the German AD industry which has been able to grow and mature using cheap government loans, big incentives, and unlimited access to high-value feedstock such as maize and large grants for farmers, the British AD industry will not have these advantages and must find another way. I believe that the way forward is small 'appropriately sized' $A D$ '.

The cost of laying gas pipelines and connecting to the national grid were also mentioned as factors to be considered. 


\section{Conclusions}

Raising awareness is without doubt the most positive and necessary step in promoting AD in the UK with the recognition of its underdeveloped status. The results of this study show the various options and challenges to raising awareness of $\mathrm{AD}$ in the UK. The study also demonstrated the importance of $\mathrm{UK}$ AD stakeholders in the development of the AD industry. Therefore it is strongly suggested that there is a need for effective stakeholder engagement for the development of AD industry in the UK. There is an overlap between the benefits of AD technology and sustainable development goals, which further necessitates the development of AD in the UK. Community $\mathrm{AD}$ and localism, small AD plants, enhancement of $\mathrm{AD}$ skills and understanding, promoting the benefits of $\mathrm{AD}$ for everyone and its products are viable options for raising awareness for $\mathrm{AD}$ in the UK. However, challenges such as finance need to be addressed, and in doing so, the complexity of AD technology needs to be taken into account. Government role, both financial and non-financial, in the development of the UK AD industry cannot be overemphasized. With respect to finance, there is a need to improve on current renewable energy incentives available to farmers and investors, to make AD more attractive and to emphasize its role in waste treatment rather than just renewable energy. Networking farmers, investors and community is another role the government has to play, to accelerate AD development in the UK. The target of 1000 AD plants by 2020 set by DEFRA is a sign of the UK government's commitment to AD development (Bywater 2011). However, addressing the issues identified in this research is one way by which this target can stand a chance, even though realistically this is not likely to be achieved.

\section{Acknowledgement}

The authors will like to thank the institution where the study was based and more specifically the department of biological sciences for partly sponsoring this research.

\section{References}

Alburquerque, J. A., Fuente, C., Campoy, M., Carrasco, L., Najera, I., Baixauli, C., Caravaca, F., Roldan, A., Cegarra, J., \& Bernal, M. P. (2012). Agricultural use of digestate for horticultural crop production and improvement of soil properties, European Journal of Agronomy, 43, 119-128. http://dx.doi.org/10.1016/j.eja.2012.06.001

Anon, K. A. (1989) Sustainable development and natural resources management, Conference Twenty-fifth Session. Rome: FAO.

Bi, L., \& Haight, M. (2007) Anaerobic digestion and community development: A case study from Hainan province, china. Environment, Development and Sustainability, 9(4), 501-521. http://10.1007/s10668-006-9034-7

Browne, J. D., Allen, E., \& Murphy, J. D. (2013). Evaluation of the biomethane potential from multiple waste streams for a proposed community scale anaerobic digester. Environmental Technology, 34(13-16), 2027-2038. http://10.1080/09593330.2013.812669

Bywater, A. (2011). A Review of Anaerobic Digestion Plants on UK Farms- Barriers, Benefits and Case Studies A report prepared with financial support from the Frank Parkinson 
Agricultural trust. Warwickshire: RASE

DEFRA: Department for Environment, Food and Rural Affairs (2011). Anaerobic Digestion Strategy and Action Plan- A commitment to increasing energy from waste through Anaerobic Digestion. London: DEFRA. Retrieved June 10, 2013, from https://www.gov.uk/government/uploads/system/uploads/attachment_data/file/69400/anaerob ic-digestion-strat-action-plan.pdf

DEFRA: Department for Environment, Food and Rural Affairs (2012). Anaerobic Digestion Strategy and Action Plan- Annual Report on Progress 2011/2012, July 2012. London: DEFRA. $\quad$ Retrieved June $10, \quad 2013$, from https://www.gov.uk/government/uploads/system/uploads/attachment_data/file/69566/pb1378 8-ad-2012-progress.pdf

Frith, P., \& Gilbert, J. (2011). Anaerobic Digestion Evidence Availability and Gap Analysis Report to Defra, project number WR1311.

Ingram, J. (2008). Are farmers in England equipped to meet the knowledge challenge of sustainable soil management? An analysis of farmer and advisor views, Journal of Environmental Management, 86, 214-228. http://dx.doi.org/10.1016/j.jenvman.2006.12.036

Khan, J. (2002). Siting conflicts in renewable energy projects: A biogas case study, cited in; A. Boholm and R. Löfstedt (Eds.) (2005) Facility Siting: Risk, Power and Identity in Land-Use Planning, London: Earthscan

Kim, W., Lee, S., Lee, C., Shin, S. G., Hwang, S., \& Hwang, K. (2010). Methanogenic community shift in anaerobic batch digesters treating swine wastewater. Water Research, 44(17), 4900-4907. http://dx.doi.org/10.1016/j.watres.2010.07.029

Levidow, L. \& Papaioannou, T. (2013). State imaginaries of the public good: shaping UK innovation priorities for bioenergy. Environmental Science \& Policy, 30, 36-49. http://dx.doi.org/10.1016/j.envsci.2012.10.008

Lukehurst, C., (2007). Esbjerg-Denmark, AD on the move-United Kingdom 2007, cited in: Zglobisz, N., Castillo-Castillo, A., Grimes, S. and Jones, P. (2010) Influence of UK energy policy on the deployment of anaerobic digestion. Energy Policy, 38, 5988-5999. http://dx.doi.org/10.1016/j.enpol.2010.05.054

Opdenakker, R. (2006). Advantages and Disadvantages of Four Interview Techniques in Qualitative Research. Forum: Qualitative Social Research, 7(4), Art. 11.

Parliamentary Office of Science and Technology (2011). Anaerobic Digestion. Postnote, No. 387, London: POST

Perez, I., Garfi, M., Cadena, E., \& Ferrer, I. (2014). Technical, economic and environmental assessment of household biogas digesters for rural communities, Renewable Energy, 62, 313-318. http://dx.doi.org/10.1016/j.renene.2013.07.017

Surendra, K. C., Takara, D., Jasinski, J., \& Khanal, S. K. (2013). Household anaerobic digester 


\section{Macrothink}

for bioenergy production in developing countries: Opportunities and challenges. Environmental Technology, 34(13-16), 1671-1689. http://10.1080/09593330.2013.824012

Swindal, M. G., Gillespie, G. W., \& Welsh, R. J. (2010). Community digester operations and dairy farmer perspectives. Agriculture and Human Values, 27(4), 461-474. http://10.1007/s10460-009-9238-1

Thomsen, I. K., Olesen, J. E., Moller, H. B., Sorensen, P., \& Christensen, B. T. (2013). Carbon dynamics and retention in soil after anaerobic digestion of dairy cattle feed and faeces. Soil Biology \& Biochemistry, 58, 82-87.

WCED: World Commission on Environment and Development (1987). Our Common Future. Brundtland Report. Oxford: Oxford University Press for WCED.

Wilkinson, K. G. (2011). A comparison of the drivers influencing adoption of on-farm anaerobic in Germany and Australia. Biomass and Bioenergy, 35, 1613-1622. http://dx.doi.org/10.1016/j.biombioe.2011.01.013

Zglobisz, N., Castillo-Castillo, A., Grimes, S., \& Jones, P. (2010). Influence of UK energy policy on the deployment of anaerobic digestion. Energy Policy, 38, 5988-5999. http://dx.doi.org/10.1016/j.enpol.2010.05.054

\section{Copyright Disclaimer}

Copyright for this article is retained by the author(s), with first publication rights granted to the journal.

This is an open-access article distributed under the terms and conditions of the Creative Commons Attribution license (http://creativecommons.org/licenses/by/3.0/). 